\title{
A Short Review of Techniques for Phenol Removal from Wastewater
}

\author{
Laura G. Cordova Villegas ${ }^{1} \cdot$ Neda Mashhadi $^{2} \cdot$ Miao Chen $^{2} \cdot$ Debjani Mukherjee $^{1}$. \\ Keith E. Taylor ${ }^{2} \cdot$ Nihar Biswas ${ }^{1}$
}

Published online: 7 May 2016

(C) Springer International Publishing AG 2016

\begin{abstract}
Phenolic compounds are priority pollutants with high toxicity even at low concentrations. In this review, the efficiency of both conventional and advanced treatment methods is discussed. The applicability of these treatments with phenol and some common derivatives is compared. Conventional treatments such as distillation, absorption, extraction, chemical oxidation, and electrochemical oxidation show high efficiencies with various phenolic compounds, while advanced treatments such as Fenton processes, ozonation, wet air oxidation, and photochemical treatment use less chemicals compared to the conventional ones but have high energy costs. Compared to physicochemical treatment, biological treatment is environmentally friendly and energy saving, but it cannot treat high concentration pollutants. Enzymatic treatment has proven to be the best way to treat various phenolic compounds under mild conditions with different enzymes such as peroxidases, laccases, and tyrosinases. This review covers papers from 2013 through January 2016.
\end{abstract}

Keywords Phenol $\cdot$ Remediation · Wastewater · Hazardous · Treatment $\cdot$ Degradation

This article is part of the Topical Collection on Water Pollution

Keith E. Taylor

taylor@uwindsor.ca

1 Department of Civil and Environmental Engineering, University of Windsor, 401 Sunset Avenue, Windsor, ON, Canada N9B 3P4

2 Department of Chemistry and Biochemistry, University of Windsor, 401 Sunset Avenue, Windsor, ON, Canada N9B 3P4

\section{Introduction}

Phenolic compounds are present in the effluents of various industries such as oil refining, petrochemicals, pharmaceuticals, coking operations, resin manufacturing, plastics, paint, pulp, paper, and wood products [1-3]. Discharge of these compounds without treatment may lead to serious health risks to humans, animals, and aquatic systems [1]. Phenol has been designated as a priority pollutant by the US Environmental Protection Agency (EPA) and the National Pollutant Release Inventory (NPRI) of Canada [4, 5]. International regulatory bodies have set strict discharge limits for phenols for a sustainable environment [1]. For example, the EPA has set a water purity standard of less than $1 \mathrm{ppb}$ for phenol in surface water [2]. The toxicity levels usually are in the range $9-25 \mathrm{mg} / \mathrm{L}$ for both humans and aquatic life [6]. Phenol possesses hazardous health effects that can be both acute and chronic. Long-term exposure can lead to irregular breathing, muscle weakness, tremor, coma, and respiratory arrest at lethal doses in humans. Human exposure to phenol results in the irritation of the skin, eyes, and mucous membranes. Chronic effects due to phenol exposure can be anorexia, weight loss, diarrhea, vertigo, salivation, and a dark coloration of the urine. Chronic exposure to phenols leads to irritation in the gastrointestinal and central nervous systems and liver, kidney, and cardiovascular tissues in animals $[3,7,8]$. Animal studies have shown fetal body weight reduction, growth retardation, and abnormal development in the offspring. Thus, there is a need to treat wastewater affected with phenolic compounds before discharge. Phenol exists in common derivatives such as Bisphenol A (BPA) [9], chlorophenols (CPs), and phenolic endocrine disrupting compounds [10]. The technologies described in this paper for removing phenols from industrial wastewater are classified as conventional and advanced methods. 
Conventional methods have been applied such as steam distillation, liquid-liquid extraction, adsorption, solid-phase extraction, wet air oxidation, catalytic wet air oxidation, and biodegradation for removal of phenols.

Advanced technologies for removal of phenols include electrochemical oxidation, photo-oxidation, ozonation, UV/ $\mathrm{H}_{2} \mathrm{O}_{2}$, Fenton reaction, membrane processes and enzymatic treatment $[3,4,6]$. The time frame for this review was from 2013 through January 2016.

\section{Distillation}

Distillation technologies for removal of phenols from water are all variants of steam distillation and thus have an energy requirement to be economically met. The technologies are either destructive or non-destructive, the latter allowing for recovery of the phenolics [11]. Steam or azeotropic distillation based on the relative volatility of phenol is capable of purifying water containing phenol impurities [3]. In another study, aqueous phenol solution was directly introduced into a novel steam plasma torch (steam plasma jet treatment), and phenol was rapidly decomposed in the thermal plasma jet, by the production of hydroxyl radicals that caused oxidative degradation of organic pollutants in aqueous solutions [12]. The primary intermediates formed from phenol were pyrocatechol, hydroquinone, maleic acid, butanedioic acid, and muconic acid in the liquid phase, while the major gaseous products were $\mathrm{H}_{2}, \mathrm{CO}$, and $\mathrm{CO}_{2}$. Steam thermal plasmas have high enthalpy and activity while, at the same time, they are ecofriendly, which makes them popular in the field of environmental remediation.

Olive mill wastewater (OMW) is noted for its high organic load and the presence of phenolic compounds. Sklavos et al. used a solar distillation apparatus to investigate the solar drying of OMW and the recovery of phenolic compounds with antioxidant properties in the distillate. More than 50 types of phenolic compounds have been identified in OMW of which hydroxytyrosol and tyrosol are the two most common phenolic compounds detected. These two compounds have the capability to protect low-density lipoprotein (LDL) particles from oxidative damage and have been approved by the European Food Safety Authority. Solar distillation parameters like temperature of the ambient air, vapor pressure inside the apparatus, phenolic recovery, retentate (sludge) production, and solar radiation were monitored during the experiments. Solar distillation also effected OMW dewatering within a very short time. Thus, solar distillation was suggested as an economical and ecofriendly process $[13 \bullet]$.

\section{Adsorption and Extraction}

Adsorption and extraction technologies for removal of phenols from water are effective from trace concentrations to percent concentrations, depending on the economics (including energy) of using and recycling the required secondary material, adsorbent, or extractant. Activated carbon is the most used and a highly efficient adsorption method. It is expensive but has been shown to be effective for removal of trace organic compounds $[14,15 \bullet]$. Therefore, new options are being developed including chemical modification of the activated carbon, impregnation with nanoparticles, different sources of carbon, different activation methods, as well as substitution with lowcost biosorbents, such as lignocellulose and chitin/chitosan, which are promising alternatives to remove phenolic compounds $[15 \cdot, 16-19]$. Nadavala et al. studied the adsorption of phenolic compounds using pine bark, a lignocellulosic waste from forestry. The optimal $\mathrm{pH}$ was 6 , reaching biosorption equilibrium in $120 \mathrm{~min}$, with a total biosorption capacity for phenol of $143 \mathrm{mg} / \mathrm{g}$ [17]. Another possible option is the combination of activated carbon with a biosorbent. For example, Huang et al. used a composite of activated carbon and chitosan (ratio of 1:1) to remove phenol as well as chromium (VI), achieving up to $95 \%$ removal of both, reaching equilibrium in $40 \mathrm{~min}$ [20]. A chemical modification of activated carbon was developed by Carvajal-Bernal et al., in which activated carbons of two different types, granular and pelletized, were impregnated with phosphoric acid or potassium hydroxide. Both impregnations modified the surface area, micropore volume, and the volume of mesopores due to reaction with superficial oxygen groups. Phosphoric acid promoted better adsorption of 2,4-dinitrophenol. On the other hand, potassium hydroxide did not show a benefit on the adsorption process [19]. Substances like natural organic matter (NOM) can interfere in the removal of phenolic compounds such as Bisphenol A (BPA). For example, Park et al. impregnated powdered activated carbons (PACs) with different types of iron oxide nanoparticles (IONPACs) to enhance the removal of BPA in the presence of organic matter. The adsorbents were PAC, ferrihydrite/PAC, magnetite/PAC, and hematite/PAC. Electron-microscopic analysis showed that the iron was impregnated in the PAC inner pores not on the surface at 12.6$17.4 \mathrm{mg}-\mathrm{Fe} / \mathrm{g}-\mathrm{PAC}$. Equilibrium for BPA and NOM on these IONPACs was reached at $150 \mathrm{~min}$. Adsorption of BPA was similar by all the adsorbents used; but for NOM, adsorption was better with the IONPACs. The Freundlich isotherms for both compounds showed greater adsorption for IONPAC adsorbents than for PAC. For example, the Freundlich isotherm coefficient $\left(K_{\mathrm{F}}\right.$; which corresponds to the adsorption capacity at unit equilibrium BPA concentration) for PAC was 94.1 and for IONPACs they were in the range 119-270, which means a greater sorption capacity for IONPACs than for bare PAC. It was also found that if the concentration of NOM increased, the 
BPA absorbed onto PAC was decreased; however, in the IONPAC, the adsorption capacity was nearly the same in the presence of large amounts of NOM, making it more stable in the presence of organic matter and enhancing the removal of both NOM and BPA [15•].

Liquid-liquid extraction, also known as conventional solvent extraction, is a standard, non-destructive process for treatment of phenolic compounds, suitable over a wide range of phenol concentrations [21]; it is cost-effective in some circumstances. Liu et al. investigated the efficiency of using cumene as extractant for phenol in wastewater. The experiment was carried out with $100 \mathrm{mg} / \mathrm{L}$ phenol aqueous solution and three parameters (temperature, $\mathrm{pH}$, and extraction time) were studied. On the one hand, the extraction time did not have much effect on the phenol removal, whereas a change of temperature had an impact on the extent of phenol removal, for example, the phenol removal can increase $5 \%$ with a $30{ }^{\circ} \mathrm{C}$ temperature raise. The cumene extraction process was $\mathrm{pH}$-dependent, since phenol ionizes at high $\mathrm{pH}$. The method performed well over a wide range of phenol concentrations (50-2200 mg/L) [22].

Cloud-point extraction (CPE) is based on surfactants separating into two phases (coacervate and bulk aqueous solution) when the solution reaches a certain temperature, known as the cloud point. The phenolic compound will gather in the coacervate and can be separated from the surfactant by $\mathrm{pH}$ changes. El-Abbassi et al. used CPE to remove phenolic compounds from pretreated olive mill wastewater. With Triton X-100 as a surfactant, it was found that phenol removal was dependent on both the surfactant concentration and temperature. At a certain temperature above the cloud point $\left(67^{\circ} \mathrm{C}\right)$, the phenol removal extent relied less on surfactant concentration when Triton X-100 concentration was higher than $5 \%(w / w)$. However, increasing temperature achieved a higher removal, for example, when the temperature was raised from 70 to $90{ }^{\circ} \mathrm{C}$, the removal increased $20 \%$ at the same Triton X-100 concentration, due to the phenol solubility change. Phenol removal of $66.5 \%$ (initial phenolic content is $9150 \mathrm{mg} / \mathrm{L}$ ) was observed using $10 \%$ Triton X-100 at $90{ }^{\circ} \mathrm{C}$ [23].

\section{Phenol Removal by Membrane Processes}

Membrane technologies are reliable and economically feasible to treat phenol and have many advantages such as low power consumption, high quality effluent, small footprint, and easy scaling up with membrane modules. However, consideration must be given to membrane fouling which can occur due to particles and colloids present in the feed streams [3, 9]. The most important membrane technologies used to remove phenols from wastewater are extractive membrane bioreactors and hollow fiber membranes; photocatalytic membrane reactors; high-pressure membrane processes such as nanofiltration, reverse osmosis, and pervaporation; and membrane distillation [3, 9, 24].

\section{Extractive Membrane Bioreactors (EMBR) and Hollow Fiber Membranes}

An EMBR combines an aqueous-aqueous extractive membrane process and biodegradation to show high potential in treating phenol in wastewater. Loh et al. prepared composite hollow fiber membranes with different levels of polydimethylsiloxane (PDMS) intrusion by coating a layer of PDMS on a polyetherimide (PEI) hollow fiber substrate for phenol removal [24]. Praveen and Loh investigated removal of phenol from wastewater by hollow fiber membranes impregnated with trioctylphosphine oxide (TOPO), which was immobilized in the hollow fiber membrane for removal of phenol. Advantages of this process include compact design and flexible equipment configuration that makes it popular in the field of environmental engineering [25].

\section{Photocatalytic Membrane Reactors (PMRs)}

PMRs are hybrid reactors in which photocatalysis is coupled with a membrane separator that acts as a simple barrier for the photocatalyst and, at the same time, a selective barrier for the molecules to be degraded. It is necessary to remove the photocatalyst particles from treated water after degradation [3]. In other work, Vaiano et al. studied the degradation of organic matter present in tannery wastewater by means of an undoped commercial $\mathrm{TiO}_{2}$ catalyst, Degussa P25, and Ndoped titania nanoparticles under UV or visible light irradiation, respectively. It was observed that P25 was only active in the presence of UV light whereas N-doped titania was potent in treating tannery wastewater in the presence of visible light emitted by LEDs [26].

\section{Reverse Osmosis (RO) and Nanofiltration (NF)}

$\mathrm{RO}$ is a membrane-based demineralization technique that is used to separate dissolved solids, especially ions, mostly from aqueous solutions whereas NF is widely used for removing organic pollutants, inorganic salts, color, and hardness from aqueous solutions [3]. NF is suitable to use in front of an RO unit in order to decrease RO pressures associated with organic matter [27]. Sun et al. investigated pretreatment by microfiltration (MF) or ultrafiltration (UF) membranes prior to NF or RO systems to avoid fouling of membranes [1]. Mnif et al. studied removal and adsorption of phenol from aqueous solutions using a polyamide thin film composite RO membrane. The effects of parameters such as feed concentration, ionic strength, transmembrane pressure, and recovery on the elimination of phenol were studied [28]. Khazaali et al. studied 
Bisphenol A (BPA) removal from aqueous solutions using a low-pressure RO system, an improvement over conventional RO, consuming less energy, having a lower pressure requirement, good rejection, and higher water flux [9].

Kumar et al. studied phenol removal from coke-oven wastewater by cross-flow nanofiltration membranes. Four different types of composite polyamide commercial products (Sepro, USA) were tested under different operating conditions such as transmembrane pressure, $\mathrm{pH}$, and recovery rate. It was concluded that nanofiltration had improved efficiency in phenol removal from industrial wastewater [29].

\section{Pervaporation (PV)}

In recent times, $\mathrm{PV}$ has attracted attention as an alternative means of removal of low volatility organics from wastewater. The characteristic features of PV include minimal energy consumption, no secondary contamination, high efficiency, and easy operation. Generally, water and volatile organic compounds are localized at the feed and permeate side of the membrane, respectively, with simultaneous evaporation of the permeate compound. Membranes like PDMS, urethane polymers, and poly(ether block amide) (PEBA) membranes have been used for phenol removal. Previous research also suggested that PV using a PEBA 2533 membrane can be an alternative way for retrieving phenol from wastewater streams. This membrane showed good selectivity for phenol compared to PDMS and zeolite-filled PDMS membranes $[3,30]$.

\section{Membrane Distillation (MD)}

The MD process is a non-isothermal, membrane-based separation competing with other technologies like $\mathrm{RO}$, which suffer from osmotic pressure limitations [31]. In other work, Mohammadi et al. have studied phenolic wastewater treatment by vacuum membrane distillation (VMD) using the Taguchi optimization approach. A polytetrafluroethylene (PTFE) membrane with a pore size of $0.22 \mu \mathrm{m}$ was used for the process [32]. Membrane fouling and pore wetting are the major drawbacks of the MD process [31].

\section{Chemical Oxidation}

Chemical oxidants provide destructive treatments of aqueous phenols. The processes have low reagent and energy costs, operating under mild conditions (temperature and $\mathrm{pH}$ ) most commonly in the parts per million range and higher. Ozone, chlorine, chlorine dioxide, chloramines, ferrate $[\mathrm{Fe}(\mathrm{VI})]$, and permanganate $[\mathrm{Mn}(\mathrm{VII})]$ are the most common chemicals applied in oxidative treatment of wastewater. Permanganate and ferrate have been widely studied and used due to their high reduction potentials $\left(E_{\left(K M n O_{4}\right)}^{\circ}=1.68 \mathrm{~V}, E_{\left(K_{2} \mathrm{FeO}_{4}\right)}^{\circ}=2.2 \mathrm{~V}\right)$. Ferrate has the ability to oxidize various contaminants over a wide range of $\mathrm{pH}$. It reduces to ferric hydroxide which has coagulation/ flocculation properties, thus providing better efficiency. On the other hand, permanganate is relatively cheap, easy to handle (including the manganese dioxide sludge produced), stable, and does not form chlorinated or brominated by-products [33-35]. Peings et al. investigated the oxidation mechanism of phenol by sulfatoferrate (VI) and compared it with permanganate and hypochlorite. The experiment was carried out with $30 \mathrm{mg} / \mathrm{L}$ of phenol in alkaline solution ( $\mathrm{pH}$ 9) to avoid ferrate degradation. Complete transformation of phenol was achieved only with excess oxidant. For example, a molar ratio of 10 (oxidant to phenol) decreased TOC by $57 \%$ for $\mathrm{K}_{2} \mathrm{FeO}_{4}, 70 \%$ for permanganate, and $61 \%$ for $\mathrm{Ca}(\mathrm{Cl} 0)_{2}$. The reaction of ferrate (VI) and phenol followed first-order kinetics with respect to both reactants and was not influenced by the presence of impurities. Data from a spin-trapping study confirmed formation of phenoxy radical and hence a radical reaction pathway. In the case of hypochlorite, various amounts of chlorophenolic by-products were observed depending on reactant molar ratio [36].

Formation of brominated polymers by Mn (VII) was evaluated during treatment of water containing bromophenols (BrPs) by Jiang et al. A kinetic study on micromolar BrP solutions with $\left[\mathrm{MnO}_{4}^{2-}\right] /[\mathrm{BrP}]=15-40$ exhibited a bellshaped $\mathrm{pH}$ dependence of the second-order rate constant $[37 \cdot \bullet]$, consistent with formation of products following the mechanism demonstrated by $\mathrm{Du}$ et al., for chlorophenols [38]. Product analysis suggested $\mathrm{C}-\mathrm{O}$ and $\mathrm{C}-\mathrm{C}$ coupling between bromophenoxyl radicals formed through oneelectron oxidation of BrPs by Mn (VII) [37••]. The effect of ABTS (2,2 -azino-bis(3-ethylbenzothiazoline-6sulphonic acid)) as a catalyst or mediator on oxidation of substituted phenols by Mn (VII) was studied by the same group. The reaction happens through a one-electron transfer mechanism producing $\mathrm{ABTS}^{\cdot+}$ and $\mathrm{Mn}(\mathrm{VI})$. $\mathrm{ABTS}^{\cdot+}$ quickly oxidizes phenol with a greater rate than that of Mn (VII). ABTS also accelerated Fe (VI) kinetics with phenol but had no effect on milder oxidants such as $\mathrm{HOCl}$ due to a lower degree of $\mathrm{ABTS}^{\circ+}$ generation [39].

Oxidation by permanganate has been reported to be very effective in removing endocrine disrupting chemicals like Bisphenol A (BPA). Over $99 \%$ of $5 \mu \mathrm{M}$ BPA was degraded using $100 \mu \mathrm{M} \mathrm{KMnO}_{4}$ at $\mathrm{pH}$ 7. The reaction rate showed strong dependence on temperature and $\mathrm{pH}$. The proposed reaction pathway was similar to that of BPA ozonation, with the benzene ring being the reaction site in the early stages of oxidation [40]. 


\section{Electrochemical Oxidation}

Electrochemical oxidation is an alternative destructive treatment of aqueous phenols which has no reagent requirement and cost, but does incur equipment and energy costs. As previously reviewed by Martinez-Huitle et al. and Tasic et al., electrochemical oxidation techniques are divided into direct and indirect oxidation. Direct or anodic treatment happens through adsorption of the pollutants onto the anode surface. Various anode materials are used with $\mathrm{Pt}, \mathrm{PbO}_{2}, \mathrm{SnO}_{2}, \mathrm{IrO}_{2}$, and BDD (boron-doped diamond) being the most investigated ones. Parameters such as current density, $\mathrm{pH}$, anode material, and electrolytes used influence treatment efficiency. Degradation of phenol follows pseudo first-order kinetics and the effectiveness of the process is indicated by apparent current efficiency, electrochemical oxidation index, or instantaneous current efficiency. Indirect oxidation takes advantage of intermediary redox reagents to effect electron transfer between electrode and pollutant, thereby preventing electrode fouling by contaminants. The presence of chloride ions enhances removal of phenolic compounds through the formation of $\mathrm{Cl}_{2}$ or $\mathrm{ClO}^{-}$in a process called electrochemical oxidation of active chlorine [41, 42•].

Rabaaoui et al. investigated the electrochemical oxidation of $o$-nitrophenol at a BDD electrode, which has the highest potential value for oxygen evolution among other conventional electrodes. In nitrophenols, regardless of the relative position of $-\mathrm{OH}$ and $-\mathrm{NO}_{2}$ groups, after $8 \mathrm{~h}, 96 \%$ mineralization was achieved with all samples at $60 \mathrm{~mA} \mathrm{~cm}^{-2}$ and $\mathrm{pH} 3$. The group found $o$-nitrophenol degradation was the fastest in the presence of $\mathrm{Na}_{2} \mathrm{SO}_{4}$ in comparison with $\mathrm{NaCl}$ and $\mathrm{KCl}$ and is more efficient in acidic medium. Based on ionchromatographic data, the group suggested a mineralization pathway through carboxylic acids by hydroxyl radicals $\left(\mathrm{OH}^{*}\right)$ and total transformation of organic nitrogen to $\mathrm{NH}_{4}{ }^{+}$and $\mathrm{NO}_{3}{ }^{-}$ions [43].

Gupta et al. studied interaction of the most influential parameters on degradation of 2,4-dinitrophenol in both batch and continuous-flow reactors using a $\mathrm{PbO}_{2}$ electrode coated on steel. Their statistical optimization found $\mathrm{pH} 6.59, \mathrm{NaCl}$ concentration of $1.12 \mathrm{~g} / \mathrm{L}$, and current of $1.44 \mathrm{~mA} / \mathrm{cm}^{2}$ predicted $94.2 \%$ chemical oxygen demand (COD) removal in a batch reactor, which was confirmed by obtaining $93.9 \%$ COD removal experimentally. A continuous-flow reactor showed the same COD removal trend using $0.5 \mathrm{~g} / \mathrm{L}$ of electrolyte with $500 \mathrm{~mL} / \mathrm{h}$ flow at a current density of $58 \mathrm{~mA} / \mathrm{cm}^{2}$ [44]. Hurwitz et al. designed a photo-assisted electrochemical (UVEL) reactor with BDD and ruthenium oxide on titanium (DSA-Cl ${ }_{2}$ ) as anodes to study the effect of an advanced oxidation process (AOP) and electrochemical hybrid techniques on phenol treatment. The experiment was conducted in the presence and absence of chlorine for $6 \mathrm{~h}$ at a current density of $20 \mathrm{~mA} / \mathrm{cm}^{2}$. DSA-Cl ${ }_{2}$ showed higher free-chlorine generation and TOC removal than BDD. In the absence of chloride, BDD led to $71 \%$ TOC removal using UVEL whereas DSA- $\mathrm{Cl}_{2}$ showed only $43 \%$. Addition of chloride enhanced TOC removal in DSA- $\mathrm{Cl}_{2}$ up to $96 \%$ but had no effect with BDD. UVEL had a synergic effect on removal of phenol TOC with both DSA-Cl ${ }_{2}$ and BDD [45]. Based on the results of $\mathrm{Chu}$ et al., the electro-Fenton oxidation process can enhance biodegradability of $m$-cresol using $\mathrm{Ti} / \mathrm{SnO}_{2}-\mathrm{Sb}_{2} \mathrm{O}_{5^{-}}$ $\mathrm{IrO}_{2}$ as anode, and a porous carbon PTFE composite as cathode. $m$-Cresol decay depended on $\left(\mathrm{OH}^{\circ}\right)$ generated in bulk solution through Fenton reaction as well as that formed at the anode. Total destruction of $100 \mathrm{mg} / \mathrm{L} m$-cresol was achieved at $\mathrm{pH} 3$ with $22.4 \mathrm{mg} / \mathrm{L}$ of $\mathrm{Fe}^{2+}$ in $2 \mathrm{~h}$ [46].

\section{Advanced Oxidation Processes (AOPs)}

AOPs are an array of techniques having the common feature that they form hydroxyl radical $\left(\mathrm{OH}^{*}\right)$ in situ and this free radical is capable of mineralizing most organics, including phenolics. The AOPs covered below, $\mathrm{UV} / \mathrm{H}_{2} \mathrm{O}_{2}$, Fenton, wet air oxidation, and ozone, are variously applicable across a wide concentration range of the phenolic target compounds.

\section{Phenol Removal by $\mathrm{UV} / \mathrm{H}_{2} \mathrm{O}_{2}$ Treatment}

Microwave (MW) irradiation is a useful adjunct for $\mathrm{UV} / \mathrm{H}_{2} \mathrm{O}_{2}$ wastewater treatment, leading to shorter reaction time, reduction in the activation energy, smaller equipment size, greater ease of operation, and high product yield. For example, a MW irradiation at $2.5 \mathrm{GHz}$ combined with a $\mathrm{UV} / \mathrm{H}_{2} \mathrm{O}_{2}$ system improved the oxidative decomposition of phenol. Although a greater amount of $\mathrm{H}_{2} \mathrm{O}_{2}$ was needed for mineralization in aqueous solution, conversion of phenol and the TOC removal efficiency increased up to $50 \%$ [3]. In another study, Karci et al. studied degradation and detoxification of industrially important phenol derivatives in water by a direct UV-C photolysis and by a UV-C/ $\mathrm{H}_{2} \mathrm{O}_{2}$ process. 2,4-Dichlorophenol (2, 4-DCP) and the non-ionic industrial surfactant nonylphenol decaethoxylate (NP-10) were compared in the two processes with respect to changes in parent pollutant, total organic carbon (TOC), oxidation products, and acute toxicity to the marine photobacterium Vibrio fischeri. The UV-C/ $\mathrm{H}_{2} \mathrm{O}_{2}$ process was better than direct UV-C photolysis in terms of parent compound and TOC removals. It was further observed that UV-C/ $\mathrm{H}_{2} \mathrm{O}_{2}$ treatment for 90 min led to complete degradation of the parent compound and achieved 95 and $78 \%$ TOC removals for 2,4-DCP and NP-10, respectively [47]. Another study was conducted by Zhang and Li for the removal of phenolic endocrine disrupting compounds (EDCs) such as steroid estrogens, $17 \beta$-estradiol, estriol, $17 \alpha$-ethinylestradiol, phenolic xenoestrogens (such as 4-nonylphenols, 4-NP), and Bisphenol A (BPA) from waste activated sludge (WAS) using 
$\mathrm{UV}, \mathrm{H}_{2} \mathrm{O}_{2}$, and $\mathrm{UV} / \mathrm{H}_{2} \mathrm{O}_{2}$. It was observed that the combined $\mathrm{UV} / \mathrm{H}_{2} \mathrm{O}_{2}$ process was more efficient in degrading organic micropollutants and WAS solubilization in water, than UV irradiation or $\mathrm{H}_{2} \mathrm{O}_{2}$ oxidation alone, due to photolysis of $\mathrm{H}_{2} \mathrm{O}_{2}$-generating hydroxyl radicals [10].

\section{Fenton and Fenton-Like Treatment}

The Fenton reagent, $\mathrm{H}_{2} \mathrm{O}_{2}$ and ferrous ion at low $\mathrm{pH}$, is an AOP capable of oxidizing aromatic pollutants. The iron (II) reacts with hydrogen peroxide to form iron (III) and hydroxyl radicals. Iron (III) is regenerated back to Fe (II) by hydrogen peroxide in an acidic environment. Also, the Fenton process has variants, such as Fenton-like, photo-Fenton, and electroFenton processes for enhancement [48, 49•, 50-53].

The classic Fenton process can be used as a pre-treatment method to reduce the toxicity of pollutants. Amor et al. investigated the combination of a Fenton process and an anaerobic biological process to treat olive mill wastewater (OMW). The OMW was too toxic for direct biological treatment, due to the presence of polyphenols and high concentrations of phenolic compounds ( 2 to $80,000 \mathrm{mg} / \mathrm{L}$ ). With a Fenton pretreatment method, they removed $82.5 \%$ polyphenol at $\mathrm{pH} 3.5$ after $8 \mathrm{~h}$ reaction, producing an effluent suitable for anaerobic treatment [48]. In another study done by Madani et al., $\mathrm{pH}$, temperature, and hydrogen peroxide concentration were investigated in a Fenton process with OMW. The suitable $\mathrm{pH}$ was $3-4$; if $\mathrm{pH}$ was lower $(<3)$, some iron (II) would be present in the $\mathrm{Fe}(\mathrm{OH})^{2+}$ which form and slow the formation of hydroxyl radicals; when the $\mathrm{pH}$ was higher $(>4)$, the regeneration of iron (II) was slowed by the precipitation of ferric oxyhydroxides and the formation of buffer-iron (II) complexes which slowed the formation of hydroxyl radicals [49•]. Temperature only had a slight effect while hydrogen peroxide concentration could be a critical factor, depending on the iron salt concentration. In both studies using a Fenton process to treat OMW, it was found that when the $\mathrm{H}_{2} \mathrm{O}_{2} / \mathrm{Fe}^{2+}$ molar ratio was at around 15 , the process reached optimum removal in both COD and total phenol concentration [48, 49•].

The Fenton-like process uses iron (III) as catalyst to turn the reaction from homogeneous to heterogeneous and is cheaper and more efficient compared to the classic Fenton process while having a similar mechanism [50, 51]. According to Pariente et al., with a Santa Barbara Amorphous-15 (SBA-15) silica-supported iron oxide $\left(\mathrm{Fe}_{2} \mathrm{O}_{3} /\right.$ SBA-15) as catalyst, nearly $99 \%$ of phenol can be removed using this process at $160{ }^{\circ} \mathrm{C}$ in an acidic environment. They also found that iron leaching was reduced as reaction temperature increased [50]. In other research, Kuan et al., using $\mathrm{FeO}_{\mathrm{x}} / \mathrm{TiO}_{2}$ as catalyst for 4-chlorophenol (4-CP) treatment, suggested that although the catalyst was in heterogeneous form, the reaction actually occurred in homogeneous solution. After a 6.5 -h reaction in acidic environment, the concentration of $\mathrm{Fe}$ ions increased from 0.8 to $30 \mu \mathrm{M}$, the concentration of 4-CP decreased from $0.4 \mathrm{mM}$ to nearly 0 [51].

A change of catalyst in a Fenton-like process can reduce its pH dependence. Kuan et al. also studied $\mathrm{CuFe}_{2} \mathrm{O}_{4}$ as a catalyst in 4-CP treatment. With the addition of copper, 4-CP removal after 30 min reaction at $\mathrm{pH} 7.4$ was $99 \%$. They suggested that neutral $\mathrm{pH}$ allows $\mathrm{Cu}^{2+}$ and $\mathrm{Fe}^{3+}$ leaching from the catalyst, which then convert 4-CP homogeneously. However, they indicated that in the buffer system used, this leaching was not a problem for the effluent since the metal ion concentration would decrease after the degradation of 4-CP. They suggested that the $\mathrm{H}^{+}$generated from 4-CP degradation was the cause for $\mathrm{Fe}$ and $\mathrm{Cu}$ ions' dissolution; when 4-CP was fully degraded, the $\mathrm{H}^{+}$concentration decreased and caused a reverse dissolution reaction of $\mathrm{CuFeO}_{2}$, which in an unbuffered system cannot happen [51].

The photo-Fenton process, a combination of UV with Fenton or Fenton-like conditions, is a more efficient and less $\mathrm{pH}$-dependent treatment method. Hydrogen peroxide can generate hydroxyl radicals under UV light and iron (III) can accept a UV photon to regenerate iron (II) [52]. According to Mofrad et al., the photo-Fenton reaction was less $\mathrm{pH}$ dependent than the Fenton process; the phenol removal rate was $60 \%$ at $\mathrm{pH} 2$ and $70 \%$ at $\mathrm{pH} 5$ [52]. UV wavelength also plays an important role in photo-Fenton process. Hadjltaief et al. pointed out that using both UV-C $(\lambda=254 \mathrm{~nm})$ and UV-A $(\lambda=365 \mathrm{~nm})$ can achieve $100 \%$ phenol degradation, but UV-C was more efficient than UV-A since the reaction time of UV-C was $30 \mathrm{~min}$ and UV-A was $60 \mathrm{~min}$. Catalyst leaching was not significant in this experiment; the concentration of metal ion was only $0.5 \mathrm{ppm}$ in the effluent [53].

\section{Wet Air Oxidation (WAO) and Catalytic Wet Air Oxidation (CWAO)}

Wet air oxidation (WAO) can be used to treat toxic organic wastewater, which is recalcitrant to biological treatment, with only high temperature and high pressure (WAO) or with a combination of high temperature, high pressure, and catalysts (CWAO). In this process, oxidizable organics, like phenol and phenolic compounds in water, are mixed with gaseous oxygen (normal air or oxygen alone) at temperatures from 150 to $400{ }^{\circ} \mathrm{C}$ and pressures from 2 to $40 \mathrm{MPa}$ [54]. The concentration of oxygen in water is much higher than at atmospheric pressure, and the water remains in the liquid phase. The oxidation reactions in WAO turn phenolic compounds into less toxic end products, such as carboxylic acids, carbon dioxide, or other harmless small molecular weight products [55].

WAO is a temperature-dependent process. Weber et al. found out that resorcinol removal in wood processing wastewater was increased from 27 to $97.5 \%$ when the temperature was 
raised from 150 to $230{ }^{\circ} \mathrm{C}$ [55]. Chen and Cheng used both WAO and CWAO to treat refinery wastewater (volatile phenols concentration was $36.8 \mathrm{~g} / \mathrm{L}$ ). For example, at an air pressure of $2 \mathrm{MPa}$ in a mixed reactor, WAO only achieved phenolic compound conversions of 13 and $42 \%$ at 150 and $200{ }^{\circ} \mathrm{C}$, respectively. With a $\mathrm{MnO}_{\mathrm{x}}-\mathrm{CeO}_{\mathrm{x}} / \gamma-\mathrm{Al}_{2} \mathrm{O}_{3}$ catalyst under the same conditions, phenolics removal improved from 42 to $74 \%$ [54].

Two types of catalysts are used in CWAO, transition metal oxides and supported noble metals. Espinosa de Los Monteros et al. investigated $\mathrm{TiO}_{2}-\mathrm{CeO}_{2}$ supported noble metals $(\mathrm{Ru}, \mathrm{Pt})$ in a CWAO process for phenol at $190^{\circ} \mathrm{C}$ and $0.2 \mathrm{MPa}$ oxygen pressure. The Pt-based catalyst had nearly $50 \%$ more phenol conversion in 20 min than the Ru-based one on the same support, which they believed was affected by the number of Lewis acid sites on these two metals. However, the amount of $\mathrm{CeO}_{2}$ on the support had a larger negative impact on the Ptbased catalyst than the Ru-based one, due to changes in the oxygen storage capacities (OSC) of the support. It was suggested that as the amount of $\mathrm{CeO}_{2}$ increased, the OSC increased and caused polymerization of the phenol, thereby poisoning the catalysts [56].

In another study, Tu et al. investigated iron oxide supported on sewage sludge-derived carbon (FeSC) as catalyst in CWAO for 2-chlorophenol (2-CP) degradation. They observed an additional $80 \% 2$-CP removal in the presence of FeSC compared to just sewage sludge-derived carbon. Also, the FeSC showed $20 \%$ more 2-CP conversion than the classical $\mathrm{Ru} / \mathrm{ZrO}_{2}$ catalyst after $5 \mathrm{~h}$ reaction. However, the FeSC suffered some leaching, in effect turning the heterogeneous reactions into homogeneous ones. Their CWAO process created an acidic environment ( $\mathrm{pH} 2$ ) resulting in $7 \mathrm{wt} \%$ iron being leached. Buffering the $\mathrm{pH}$ at 4.5 resulted in only $0.2 \mathrm{wt} . \%$ iron being leached; however, the 2-CP removal dropped from 100 to $42 \%$ [57].

\section{Ozone}

Ozonation involves either direct reaction between molecular ozone $\left(\mathrm{O}_{3}\right)$ and the dissolved compounds or further transformation of $\mathrm{O}_{3}$ into oxidants such as $\left(\mathrm{OH}^{*}\right)$, hydroperoxyl radicals $\left(\mathrm{HO}_{2}^{-}\right)$, and species such as $\mathrm{O}_{3}^{-}$and $\mathrm{HO}_{3}$, which then react with the target compounds [58].

Kuosa et al. studied the ozonation of $p$-nitrophenol at $\mathrm{pH} 2$, 7 , and 10 , using $t$-butanol as scavenger at $\mathrm{pH} 2$ to ensure a direct pathway reaction. The intermediates hydroquinone, catechol, 4nitrocatechol, oxalic acid, maleic acid, and fumaric acid were detected. At a basic $\mathrm{pH}(\mathrm{pH} 10)$, production of the intermediate oxalic acid was fast, while at $\mathrm{pH} 7$ it was slower. It was also found that the decomposition of $p$-nitrophenol was carried out more by the molecular ozone pathway than the radical ones and it was practically the same at $\mathrm{pH} 7$ and 10 [58]. Ozone consumption was a function of $p$-nitrophenol decomposed and it was highest when $t$-butanol is used at $2.25 \mu \mathrm{M}$. Felis and
Miksch determined the effectiveness of several advanced oxidation processes ( $\mathrm{UV}, \mathrm{UV} / \mathrm{H}_{2} \mathrm{O}_{2}, \mathrm{O}_{3}$, and $\mathrm{UV} / \mathrm{O}_{3}$ ) for nonylphenols (NPs). The $\mathrm{O}_{3}$ and $\mathrm{UV} / \mathrm{O}_{3}$ processes were done as homogeneous aqueous reactions in a flow system. In both processes, the decomposition efficiency was dependent on the initial ozone concentration. During the homogeneous ozonolysis, the initial concentration of NP was $10 \mathrm{mg} / \mathrm{L}$ and the ozone doses were $0.8,1.0$, and $2.0 \mathrm{mg} / \mathrm{L}$, achieving NP removals of 45,52 , and $60 \%$, respectively, with 3 min' reaction. For the $\mathrm{UV} / \mathrm{O}_{3}$ system with the same three ozone concentrations, the removals were 60,62 , and $75 \%$, respectively [59]. Harufmi et al. also used an AOP $\left(\mathrm{O}_{3}-\mathrm{UV}-\mathrm{TiO}_{2}\right)$ for the degradation of phenol in water. The ozone was generated by UV irradiation of the oxygen in the air (wavelength 175-242 nm), allowing for energy saving. In an $\mathrm{O}_{3}-\mathrm{UV}$ process, phenol decomposition was achieved by irradiating the sample solution with UV light as well as feeding ozone. On the other hand, in an $\mathrm{O}_{3}-\mathrm{UV}-\mathrm{TiO}_{2}$ process, the removal of phenol was achieved by coating the inside of the outer quartz glass tube with $\mathrm{TiO}_{2}$, and feeding ozone while irradiating with UV light. The decomposition of $50 \mathrm{mg} / \mathrm{L}$ and $100 \mathrm{mg} / \mathrm{L}$ phenol were reached within 120 and $240 \mathrm{~min}$, respectively, using the $\mathrm{O}_{3}-\mathrm{UV}-\mathrm{TiO}_{2}$ process, and COD removal reached $100 \%$ within $240 \mathrm{~min}$. Furthermore, $200 \mathrm{mg} / \mathrm{L}$ phenol decomposition reached rate was $84.3 \%$ after $240 \mathrm{~min}[60]$.

\section{Biological Treatment}

Biological treatment is the most commonly applied treatment for aqueous phenols and, as such, is the baseline or reference method against which the other methods covered here are often compared. The treatment is an inexpensive method, simple to design and maintain, for transforming phenolic solutions into simple end products. Jalayeri et al. investigated phenol removal in a batch system using small amounts of acclimatized activated sludge. They also studied the effects of several factors such as volume of inoculant, $\mathrm{pH}$, temperature, and initial concentration of phenol. The initial mixed liquor suspended solids (MLSS) was $2000 \mathrm{mg} / \mathrm{L}, \mathrm{pH}$ values were from 3 to 11 , temperatures in the range 25 to $40{ }^{\circ} \mathrm{C}$, phenol concentrations from 400 to $1500 \mathrm{mg} / \mathrm{L}$ as well as 1,3 , and $5 \mathrm{~mL}$ of acclimatized activated sludge; for all samples the total volume was $100 \mathrm{~mL}$ (including the sludge). At phenol concentrations of 100,200 , and $400 \mathrm{mg} / \mathrm{L}$, the optimal inoculant volume was $5 \mathrm{~mL}$ at $30^{\circ} \mathrm{C}$. Optimal removal was at $\mathrm{pH} 7(6 \mathrm{~h}$ reaction) for $200 \mathrm{mg} / \mathrm{L}$ of phenol at $30^{\circ} \mathrm{C}$; other $\mathrm{pHs}$ increased the removal time. The maximum phenol removal was at $30{ }^{\circ} \mathrm{C}$. The microorganism showed an inhibition stage when using $1500 \mathrm{mg} / \mathrm{L}$ phenol due to the toxicity of phenol. Using an acclimatized activated sludge, $1500 \mathrm{mg} / \mathrm{L}$ of phenol was removed in $80 \mathrm{~h}$ compared to non-acclimatized activated sludge which required more than $200 \mathrm{~h}$ [61, 62]. In another 
study, Rafiei et al. used hybrid membrane reactors (H-MBRs) to treat synthetic phenolic wastewater $(1000 \mathrm{mg} / \mathrm{L})$ in a hydraulic retention time of $13 \mathrm{~h}$. H-MBRs are membrane bioreactors (MBRs; also see "Phenol Removal by Membrane Processes" section, above) combined with carriers; they mitigate membrane fouling which is the principal drawback of conventional membrane processes and increase the operation life times. In this study, the authors immobilized acclimatized activated sludge on polypropylene (BF-MBR) or polyurethane carriers (BE-MBR); they used passive immobilization (bio-film on surface) and entrapment (cell trapping in polyurethane foam). For a conventional MBR, in 5 days (time of membrane fouling at $0.6 \mathrm{bar}$ ), final concentrations of phenol and COD of $301 \mathrm{mg} / \mathrm{L}$ ( $71 \%$ removal of phenol) and $822 \mathrm{mg} /$ $\mathrm{L}$ were detected, respectively. For the BF-MBR, the membrane fouling time was 9 days with $258 \mathrm{mg} / \mathrm{L}$ of phenol and $700 \mathrm{mg} / \mathrm{L}$ COD concentrations detected, meaning a $73 \%$ phenol removal. For BE-MBR, the membrane fouling time was 21 days, the phenol concentration was $3 \mathrm{mg} / \mathrm{L}$ ( $99 \%$ removal) and the COD was $200 \mathrm{mg} / \mathrm{L}$. Also, BE-MBR was tested under phenol shock loading finding a complete recovery of phenol removal after elimination of shocks [63].

Other compounds such as Bisphenol A (BPA) have been efficiently removed with biological treatments such as activated sludge [64-66]. For example, Zielińska et al. studied BPA removal using a mixed consortium of immobilized microorganisms in a nitrifying system. This system which is dominated by heterotrophic bacteria could be an effective method for BPA removal. The removal of BPA was more than $92 \%$ from an initial $10 \mathrm{mg} / \mathrm{L}$ initial concentration with $1.5 \mathrm{~h}$ of hydraulic retention time. It was also found that higher BPA concentrations resulted in a decrease in nitrification activity [66].

\section{Enzymatic Treatment}

Enzymatic treatment, taking inspiration from biological treatment, uses a biocatalyst, an enzyme, to carry out a transformation on phenolic compounds that leads to their removal from water. The process can have significant advantages (including cost-effectiveness) over conventional biological and chemical treatments, as long as the enzyme in question is available as a commodity at the right price [67•]. In the early 1980s, Klibanov and co-workers started enzymatic treatment of aromatics using horseradish peroxidase (HRP). This technique can be applied as a primary treatment or in combination with a biological unit. Ease of control, reduced sludge volume, effectiveness over wide ranges of substrate concentration, $\mathrm{pH}$, and salinity, short contact time, and no limitation due to shock loading are the major advantages of this method. Among all enzymes, oxidoreductases like laccases, tyrosinases, and peroxidases have the ability to catalyze removal of phenolic pollutants [68]. In contrast to biological treatment, the strategy involves polymerization of the target compounds, not breakdown, until the products reach their solubility limits and precipitate. In all cases, enzyme concentration is specified as standard units of activity (U) per volume.

Tyrosinases and laccases are copper-containing enzymes. Tyrosinases catalyze $o$-hydroxylation of monophenols to $O-$ diphenols followed by oxidation of $o$-diphenols to $o$-quinones. Non-enzymatic polymerization of the quinones forms insoluble products. Immobilizing tyrosinase covalently on nylon membrane, magnetic, or siliceous supports can enhance stability and industrial application of the enzyme [68, 69].

Laccases are activated by molecular oxygen (four electrons), while heme-protein peroxidases are activated by hydrogen peroxide (two electrons). They each then carry out successive oneelectron oxidation of reducing substrates like phenols to form the corresponding phenoxy radicals, and these radicals couple non-enzymatically to form dimers. Additional enzymatic cycles with these dimers lead eventually to polymers [70].

Although HRP is the most studied heme-protein peroxidase, soybean peroxidase (SBP) has received lots of attention because of numerous advantages over HRP. SBP has proven to be an effective enzyme to remove phenol [70, 71]. Immobilization techniques such as support- or carrierbinding through physico-chemical interaction, encapsulation which traps enzyme inside the pores of the support, or covalent cross-linking of enzyme functional groups have been investigated to enable large-scale enzymatic treatment [70].

Rezvani et al. immobilized SBP in a semi-permeable alginate membrane in a packed-bed bioreactor and studied the effect of different factors such as the flow rate, temperature, and $\mathrm{H}_{2} \mathrm{O}_{2}$ concentration on phenol removal. For an initial phenol concentration of $1 \mathrm{mM}$ and $2.25 \mathrm{U} / \mathrm{mL}$ enzyme, the optimal conditions obtained for a $97 \%$ removal were $56^{\circ} \mathrm{C}$, $14 \mathrm{mM} \mathrm{H}_{2} \mathrm{O}_{2}$ and $5.5 \mathrm{~mL} / \mathrm{min}$ flow rate [72].

A drawback in enzymatic treatment is inactivation of the enzyme, and one of the approaches to limit this is the use of additives. For example, Torres et al. studied the influence of the additives polyethylene glycol and Triton X-100 on the removal of phenol and other compounds from coffeeprocessing wastewater using soybean and turnip peroxidases. There was only an effect on the removal of phenol in the presence of the additives (a change in phenol oxidation of $50 \%)$ at $\mathrm{pH} 7$ using turnip peroxidase. At $\mathrm{pH} 3$ with turnip peroxidase, only Triton X-100 showed an effect in the oxidation of caffeic acid with a $22 \%$ increase. However, there was no influence on the oxidation of other phenolic compounds in the presence of these additives using SBP because previous work has shown that the additives inhibit enzyme deactivation by adsorption to solid polymeric products and in this process no precipitate formed; consistent with the proposed adsorption mechanism for inactivation [71, 73]. Recent work from this lab has further characterized the Triton X-100 effect and turned it to advantage, on the one hand, through recycling of 
precipitates carrying active SBP [74], while on the other hand, exploiting the adsorption for concentrating SBP from a dilute hull extract as a route to cost-effective production of SBP for wastewater treatment applications [75].

Another plant peroxidase, from potato pulp has been successfully used by Kurnik et al. to remove over $90 \%$ of phenol from a manufacturing industry wastewater in a $2 \mathrm{~h}$ reaction, with $2.59 \mathrm{mM} \mathrm{H}_{2} \mathrm{O}_{2}$, for phenol in the range $0.02-0.1 \mathrm{mM}$. The reaction was done over a wide range of $\mathrm{pH}(4-8)$; however, the phenol removal efficiency decreased sharply when the reaction was done at $\mathrm{pH} 10$. In addition to $\mathrm{pH}$, several concentrations of enzyme, phenol, and $\mathrm{H}_{2} \mathrm{O}_{2}$, were studied as well as range of temperatures [76].

\section{Conclusions}

Extensive research continues to be carried out on phenol removal from water, from conventional methods like adsorption on activated carbon to new technologies such as enzymatic treatment. Improvements to overcome low efficiencies and high operational costs of conventional techniques provide attractive alternatives, for example low-cost adsorbents, chemical modification on the adsorbents to increase surface area, hybrid systems like electro-Fenton to increase the efficiency of phenol removal, achieving total destruction of diverse phenol compounds. Enzymatic treatment has proven to be an effective method with more than $95 \%$ phenol removal using different peroxidases such as soybean and horseradish. New developments in the use of additives substantially mitigate enzyme inactivation, hitherto the most important drawback in industrial application of enzymatic treatment.

\section{Compliance with Ethical Standards}

Conflict of Interest On behalf of all authors, the corresponding author states that there is no conflict of interest.

\section{References}

Papers of particular interest, published recently, have been highlighted as:

- Of importance

•- Of major importance

1. Sun X, Wang C, Li Y, Wang W, We J. Treatment of phenolic wastewater by combined UF and NF/RO processes. Desalination. 2015;355:68-74.

2. Kazemi P, Peydayesh M, Bandegi A, Mohammadi T, Bakhtiari O. Stability and extraction study of phenolic wastewater treatment by supported liquid membrane using tributyl phosphate and sesame oil as liquid membrane. Chem Eng Res Des. 2014;92:375-83.
3. Mohammadi S, Kargari A, Sanaeepur H, Abbassian K, Najafi A, Mofarrah E. Phenol removal from industrial wastewaters: a short review. Desalin Water Treat. 2015;53:2215-34.

4. Emergency Planning and Community Right-to-Know Act (EPCRA) Section 313 Chemical list for reporting year 2014. Available from: http://www.epa.gov/toxics-release-inventory-triprogram/tri-chemical-list-ry-2014-including-toxic-chemicalcategories.

5. National Pollutant Release Inventory (NPRI) Substance List. Available from: https://ec.gc.ca/inrp-npri/default.asp?lang=En\&n= E2BFC2DB-1.

6. Kulkarni SJ, Kaware JP. Review on research for removal of phenol from wastewater. Int J Sci Res Publ. 2013;3:1-4.

7. EPA 2008 Toxic Release Inventory National Analysis, accessed December 2015. Available from: http://www.epa.gov/.

8. Mukherjee S, Basak B, Bhunia B, Dey A, Mondal B. Potential use of polyphenol oxidases (PPO) in the bioremediation of phenolic contaminants containing industrial wastewater. Rev Environ Sci Biotechnol. 2013;12:61-73.

9. Khazaali F, Kargari A, Rokhsaran M. Application of low-pressure reverse osmosis for effective recovery of Bisphenol A from aqueous wastes. Desalin Water Treat. 2014;52(40-42):7543-51.

10. Zhang A, Li Y. Removal of phenolic endocrine disrupting compounds from waste activated sludge using $\mathrm{UV}, \mathrm{H}_{2} \mathrm{O}_{2}$ and $\mathrm{UV} /$ $\mathrm{H}_{2} \mathrm{O}_{2}$ oxidation processes. Effects of reaction conditions and sludge matrix. Sci Total Environ. 2014;493:307-23.

11. El-Ashtoukhy ESZ, El-Taweel YA, Abdelwahab O, Nassef EM. Treatment of petrochemical wastewater containing phenolic compounds by electrocoagulation using a fixed bed electrochemical reactor. Int J Electrochem Sci. 2013;8:1534-50.

12. Ni G, Zhao G, Jiang Y, Li J, Meng Y, Wang X. Steam plasma jet treatment of phenol in aqueous solution at atmospheric pressure. Plasma Process Polym. 2013;10:353-63.

13. Sklavos S, Gatidou G, Stasinakis AS, Haralambopoulos D. Use of solar distillation for olive mill wastewater drying and recovery of polyphenolic compounds. J Environ Manag. 2015; 162:46-52. This article used a solar distillator to investigate the simultaneous solar drying of olive mill wastewater and recovery of phenolic compounds in the distillate.

14. Mukherjee R, De S. Adsorptive removal of phenolic compounds using cellulose acetate phthalate-alumina nanoparticle mixed matrix membrane. J Hazard Mater. 2014;265:8-19.

15. Park H, Koduru JR, Choo K, Lee B. Activated carbons impregnated with iron oxide nanoparticles for enhanced removal of Bisphenol A and natural organic matter. J Hazard Mater. 2015;286:315-24. This article studies the removal of Bisphenol $A$ in the presence of natural organic matter using activated carbons impregnated with iron oxide nanoparticles, showing greater sorption capabilities for both.

16. Tran VS, Ngo HH, Guo W, Zhang J, Liang S, Ton-That C. Typical low cost biosorbents for adsorptive removal of specific organic pollutants from water. Bioresour Technol. 2015;182:353-63.

17. Nadavala SK, Che Man H, Woo HS. Biosorption of phenolic compounds from aqueous solutions using pine (Pinus densiflora Sieb) bark powder. BioResources. 2014;9(3):5155-74.

18. Masomi M, Ghoreyshi AA, Najafpour GD, Mohamed ARB. Adsorption of phenolic compounds onto the activated carbon synthesized from pulp and paper mill sludge: equilibrium isotherm, kinetics, thermodynamics and mechanism studies. Int J Eng Trans A Basics. 2014;27(10):1485-94.

19. Carvajal-Bernal AM, Gómez F, Giraldo L, MorenoPirajá JC. Chemical modification of activated carbons and its effect on the adsorption of phenolic compounds. Ing Compet. 2015;17(1):109-19.

20. Huang R, Yang B, Liu Q, Liua Y. Multifunctional activated carbon/ chitosan composite preparation and its simultaneous adsorption of 
phenol and $\mathrm{Cr}(\mathrm{VI})$ from aqueous solutions. Environ Prog Sustainable Energy. 2014;33(3):814-23.

21. Rahmanian N, Jafari SM, Galanakis CM. Recovery and removal of phenolic compounds from olive mill wastewater. J Am Oil Chem Soc. 2014;91:1-18.

22. Liu J, Xie J, Ren Z, Zhang W. Solvent extraction of phenol with cumene from wastewater. Desalin Water Treat. 2013;51:3826-31.

23. El-Abbassi A, Kiai H, Raiti J, Hafidi A. Cloud point extraction of phenolic compound from pretreated olive mill wastewater. J Environ Chem Eng. 2014;2:1480-6.

24. Loh CH, Zhang Y, Goh S, Wang R, Fane AG. Composite hollow fiber membranes with different poly (dimethylsiloxane) intrusions into substrate for phenol removal via extractive membrane bioreactor. J Membr Sci. 2016;500:236-44.

25. Praveen P, Loh KC. Trioctylphosphine oxide-impregnated hollow fiber membranes for removal of phenol from wastewater. J Membr Sci. 2013;437:1-6.

26. Vaiano V, Sacco O, Stoller M, Chianese A, Ciambelli P, Sannino D. Influence of the photoreactor configuration and of different light sources in the photocatalytic treatment of highly polluted wastewater. Int J Chem React Eng. 2014;12(1):63-75.

27. Jin X, Li E, Lu S, Qiu Z, Sui Q. Coking wastewater treatment for industrial reuse purpose: combining biological processes with ultrafiltration, nanofiltration and reverse osmosis. J Environ Sci. 2013;25(8):1565-74.

28. Mnif A, Tabassi D, Ali MBS, Hamroun B. Phenol removal from water by AG reverse osmosis membrane. Environ Prog Sustain Energy. 2015;34:982-9.

29. Kumar R, Pal P. Removal of phenol from coke-oven wastewater by cross-flow nanofiltration membranes. Water Environ Res. 2013;85(5):447-55.

30. Wu Y, Tian G, Tan H, Fu X. Pervaporation of phenol wastewater with PVDF-PU blend membrane. Desalin Water Treat. 2013;51: 5311-8.

31. Shirazi MMA, Kargari A. A review on application of membrane distillation (MD) process for wastewater treatment. J Membr Sci Res. 2015;1:101-12.

32. Mohammadi T, Kazemi P. Taguchi optimization approach for phenolic wastewater treatment by vacuum membrane distillation. Desalin Water Treat. 2014;52:1341-9.

33. Yates BJ, Zboril R, Sharma VK. Engineering aspects of ferrate in water and wastewater treatment-a review. J Environ Sci Health Part A: Tox Hazard Subst Environ Eng. 2014;49(14):1603-14.

34. Guan X, He D, Ma J, Chen G. Application of permanganate in the oxidation of micropollutants: a mini review. Front Environ Sci Eng China. 2010;4(4):405-13.

35. Jiang JQ, Durai HB, Winzenbacher R, Petri M, Seitz W. Drinking water treatment by in situ generated ferrate (VI). Desalin Water Treat. 2015;55(3):731-9.

36. Peings V, Frayret J, Pigot T. Mechanism for the oxidation of phenol by sulfatoferrate (VI): comparison with various oxidants. J Environ Manag. 2015;157:287-96.

37.• Jiang J, Gao Y, Pang SY, et al. Oxidation of bromophenols and formation of brominated polymeric products of concern during water treatment with potassium permanganate. Environ Sci Technol. 2014;48(18):10850-8. The article assesses the formation of hazardous brominated polymers which can happen during the treatment of water with potassium permanganate. It also demonstrates that millimolar concentrations of oxidant can be very effective in removing phenolic compounds.

38. Du J, Sun B, Zhang J, Guan X. Parabola-like shaped pH-rate profile for phenols oxidation by aqueous permanganate. Environ Sci Technol. 2012;46(16):8860-7.

39. Song Y, Jiang J, Ma J, et al. ABTS as an electron shuttle to enhance the oxidation kinetics of substituted phenols by aqueous permanganate. Environ Sci Technol. 2015;49(19):11764-71.
40. Zhang J, Sun B, Guan X. Oxidative removal of Bisphenol A by permanganate: kinetics, pathways and influences of co-existing chemicals. Sep Purif Technol. 2013;107:48-53.

41. Martinez-Huitle CA, Ferro S. Electrochemical oxidation of organic pollutants for the wastewater treatment: direct and indirect processes. Chem Soc Rev. 2006;35(12):1324-40.

42. Tasic Z, Gupta VK, Antonijevic MM. The mechanism and kinetics of degradation of phenolics in wastewaters using electrochemical oxidation. Int J Electrochem Sci. 2014;9:3473-90. This article reviews the mechanism and kinetics of degradation of phenol and its derivatives using different electrodes and compares the effect of different electrolytes in oxidation of phenols

43. Rabaaoui N, Saad ME, Moussaoui Y, Allagui MS, Bedoui A, Elaloui E. Anodic oxidation of o-nitrophenol on BDD electrode: variable effects and mechanisms of degradation. J Hazard Mater. 2013;250:447-53

44. Pillai IM, Gupta AK. Batch and continuous flow anodic oxidation of 2,4-dinitrophenol: modeling, degradation pathway and toxicity. J Electroanal Chem. 2015;756:108-17.

45. Hurwitz G, Pornwongthong P, Mahendra S, Hoek EM. Degradation of phenol by synergistic chlorine-enhanced photo-assisted electrochemical oxidation. Chem Eng J. 2014;240:235-43.

46. Chu Y, Zhang D, Liu L, Qian Y, Li L. Electrochemical degradation of m-cresol using porous carbon-nanotube-containing cathode and $\mathrm{Ti} / \mathrm{SnO}_{2}-\mathrm{Sb}_{2} \mathrm{O}_{5}-\mathrm{IrO}_{2}$ anode: kinetics, byproducts and biodegradability. J Hazard Mater. 2013;252:306-12

47. Karci A, Alaton IA, Hanci TO, Bekbole M. Degradation and detoxification of industrially important phenol derivatives in water by direct UV-C photolysis and H/UV-C process: a comparative study. Chem Eng J. 2013;224(1):4-9.

48. Amor C, Lucas MS, García J, Dominguez JR, Heredia JB, Peres JA. Combined treatment of olive mill wastewater by Fenton's reagent and anaerobic biological process. J Environ Sci Health. 2015;50:161-8.

49. Madani M, Aliabadi M, Nasernejad B, Abdulrahman RK, Kilic MY, Kestioglu K. Treatment of olive mill wastewater using physico-chemical and Fenton processes. Desalin Water Treat. 2015;53(8):2031-40. This paper suggests that the Fenton treatment is more efficient than the traditional physicochemical ones for olive mill wastewater. The Fenton process is environmentally friendlier and suitable for treating OMW.

50. Pariente MI, Molina R, Melero JA, Botas JÁ, Martínez F. Intensified-Fenton process for the treatment of phenol aqueous solutions. Water Sci Technol. 2015;71(3):359-65.

51. Kuan CC, Chang SY, Schroeder SLM. Fenton-like oxidation of 4chlorophenol: homogeneous or heterogeneous? Ind Eng Chem Res. 2015;54(33):8122-9.

52. Mofrad MR, Nezhad ME, Akbari H, Atharizade M, Miranzadeh MB. Evaluation of efficacy of advanced oxidation processes Fenton, Fenton-like and photo-Fenton for removal of phenol from aqueous solutions. J Chem Soc Pak. 2015;37(2):266-71.

53. Hadjltaief HB, Zina MB, Galvez ME, Costa PD. Photo-Fenton oxidation of phenol over a Cu-doped Fe-pillared clay. C R Chim. 2015;18(10):1161-9.

54. Chen $\mathrm{C}$. Wet air oxidation and catalytic wet air oxidation for refinery spent caustics degradation. J Chem Soc Pak. 2013;35(2):244 50

55. Weber B, Chavez A, Mejia JM, Eichenauer S, Stadlbauer EA, Almanza R. Wet air oxidation of resorcinol as a model treatment for refractory organics in wastewaters from the wood processing industry. J Environ Manag. 2015;161:137-43.

56. Espinosa de Los Monteros A, Lafaye G, Cervantes A, Angel GD, Barbier Jr J, Torres G. Catalytic wet air oxidation of phenol over metal catalyst $(\mathrm{Ru}, \mathrm{Pt})$ supported on $\mathrm{TiO}_{2}-\mathrm{CeO}_{2}$ oxides. Catal Today. 2015;258(2):564-9. 
57. Tu Y, Xiong Y, Tian S, Kong L, Descorme C. Catalytic wet air oxidation of 2-chlorophenol over sewage sludge-derived carbonbased catalysts. J Hazard Mater. 2014;276:88-96.

58. Kuosa M, Kallas J, Häkkinen A. Ozonation of p-nitrophenol at different $\mathrm{pH}$ values of water and the influence of radicals at acidic conditions. J Environ Chem Eng. 2015;3(1):325-32.

59. Felis E, Miksch K. Nonylphenols degradation by means of UV, $\mathrm{UV} / \mathrm{H}_{2} \mathrm{O}_{2}, \mathrm{O}_{3}$ and $\mathrm{UV} / \mathrm{O}_{3}$. Water Sci Technol. 2015;71:446-53.

60. Harufumi S, Sadao A, Hideki Y. Evaluation of advanced oxidation processes (AOP) using $\mathrm{O}_{3}$, UV, and $\mathrm{TiO}_{2}$ for the degradation of phenol in water. J Water Process Eng. 2015;7:54-60.

61. Jalayeri H, Doulati Ardejani F, Marandi R, Rafiee pur S. Biodegradation of phenol from a synthetic aqueous system using acclimatized activated sludge. Arab J Geosci. 2013;6(10):3847-52.

62. Moussavi G, Ghodrati S, Mohseni-Bandpei A. The biodegradation and COD removal of 2-chlorophenol in a granular anoxic baffled reactor. J Biotechnol. 2014;184:111-7.

63. Rafiei B, Naeimpoor F, Mohammadi T. Bio-film and bio-entrapped hybrid membrane bioreactors in wastewater treatment: comparison of membrane fouling and removal efficiency. Desalination. 2014;337(1):16-22.

64. Pookpoosa I, Jindal R, Morknoy D, Tantrakarnapa K. Occurrence and efficacy of Bisphenol A (BPA) treatment in selected municipal wastewater treatment plants, Bangkok, Thailand. Water Sci Technol. 2015;72(3):463-71.

65. Ferro Orozco AM, Contreras EM, Zaritzky NE. Biodegradation of Bisphenol A and its metabolic intermediates by activated sludge: stoichiometry and kinetics analysis. Int Biodeterior Biodegrad. 2016;106:1-9.

66. Zielińska M, Cydzik-Kwiatkowska A, Bernat K, Bułkowska K, Wojnowska-Baryła I. Removal of Bisphenol A (BPA) in a nitrifying system with immobilized biomass. Bioresour Technol. 2014; 171:305-13

67. Steevensz A, Cordova Villegas LG, Feng W, Taylor KE, Bewtra JK, Biswas N. Soybean peroxidase for industrial wastewater treatment: a mini review. J Environ Eng Sci. 2014;9(3):181-6. This article assesses the effect of different additives in enzymatic treatment of synthetic and real wastewater with soybean peroxidase.

68. Xu DY, Yang Z. Cross-linked tyrosinase aggregates for elimination of phenolic compounds from wastewater. Chemosphere. 2013;92(4):391-8.

69. Mukherjee S, Basak B, Bhunia B, Dey A, Mondal B. Potential use of polyphenol oxidases (PPO) in the bioremediation of phenolic contaminants containing industrial wastewater. Rev Environ Sci Biol. 2013;12(1):61-73.

70. Ba S, Arsenault A, Hassani T, Jones JP, Cabana H. Laccase immobilization and insolubilization: from fundamentals to applications for the elimination of emerging contaminants in wastewater treatment. Crit Rev Biotechnol. 2013;33(4):404-18.

71. Steevensz A, Madur S, Feng W, Taylor KE, Bewtra JK, Biswas N. Crude soybean hull peroxidase treatment of phenol in synthetic and real wastewater: enzyme economy enhanced by Triton X-100. Enzym Microb Technol. 2014;55:65-71.

72. Rezvani F, Azargoshasb H, Jamialahmadi O, Hashemi-Najafabadi S, Mousavi SM, Shojaosadati SA. Experimental study and CFD simulation of phenol removal by immobilization of soybean seed coat in a packed-bed bioreactor. Biochem Eng J. 2015;101:32-43.

73. Torres J, Chagas P, Silva M, Dos Santos C, Correa A. Evaluation of the protective effect of chemical additives in the oxidation of phenolic compounds catalyzed by peroxidase. Environ Technol. 2016;37(10):1288-95.

74. Feng W, Taylor KE, Biswas N, Bewtra JK. Soybean peroxidase trapped in product precipitate during phenol polymerization retains activity and may be recycled. J Chem Technol Biotechnol. 2013;88(8):1429-35.

75. Feng W, Taylor KE, Biswas N, Bewtra JK. Phenolic precipitates from soybean peroxidase-catalyzed wastewater treatment: concentrated waste serves to concentrate its progenitor. J Hazard Toxic Radioact Waste. 2015. doi:10.1061/(ASCE)HZ.2153-5515. 0000310.

76. Kurnik K, Treder K, Skorupa-Klaput M, Tretyn A, Tyburski J. Removal of phenol from synthetic and industrial wastewater by potato pulp peroxidases. Water Air Soil Pollut. 2015;226(8):254. 